\title{
Wise use of water in smart cities - possibilities and limitations
}

\author{
Joanna Bąk $^{1, *}$ \\ ${ }^{1}$ CUT, Institute of Water Supply and Environmental Protection, 31-155 Cracow, 24 Warszawska \\ Street, Poland
}

\begin{abstract}
The need to save water is due, inter alia, to the paradigm of sustainable development. There are many ways to minimize the consumption of high quality water supplied by the water supply network. These include the simplest way and those complex, requiring additional installation. The lack of water is a big problem, but not only water deficit are dangerous. There is a possibility of secondary water pollution in the water supply network due to changes in network parameters. Changes in these parameters may occur due to reduced demand for water by residents and, as a result, reduced water flow - at the same pipe diameter. The article includes a review with comparative analysis of various classification systems for the tap fittings and other sanitary equipment, such as the Water Efficiency Label (WELL) in Europe or the Water Efficiency Labelling and Standards (WELS) in Australia. Several types of perlators and flow regulators were compared in the research section. This equipment was tested in the household. The possibilities of minimizing water consumption by using them was collated. In addition, the work also analyses the evolution of water consumption in Poland in recent years and their possible relationship with the threats quality of drinking water supplied to consumers.
\end{abstract}

\section{Introduction}

Water is essential for human life and other living organisms. Access to high quality water is a key issue for human life. Therefore, it is very important to protect water resources and minimize water consumption in households, public buildings, businesses and factories. The need to save water also arises from sustainable development goals and the paradigm of sustainable development. This task is of particular importance in modern and constantly developing cities, where the population is constantly growing. Remember that even in such a situation, minimizing water consumption is most dependent on the water demand of individual human beings (bypassing the industry). In implementing the directions for sustainable progress and, in particular, sustainable consumption, it is extremely important to draw attention at the same time to the need to adapt existing infrastructure to the changing needs of society.

\footnotetext{
* Corresponding author: jbak@pk.edu.pl
} 
The aim of this paper is to try to answer the question of the current water saving potential in modern smart cities and whether there are any drawbacks or limitations for wise use of water. The purpose of the research was to find out if drinking water in household can still be saved in cheap ways. If so, how much?

\subsection{Possibilities of wise use of water}

There are many ways to minimize the consumption of high quality water supplied by the water supply network. These include the simplest and cheapest ones such as flow regulators, as well as those requiring complex systems and additional installations such as the use of grey and rain water. Note that their effectiveness varies. Sometimes a simple solution that is a small investment may prove to be more effective than a complex installation requiring complete refurbishment for existing buildings. Ways to reduce water use in households can be classified into several groups. These include the following:

- consumer behaviour

- kitchen and bathroom equipment

- use water from other source than the water supply network (greywater and rainwater).

The consumer behaviour group includes eliminating consumer misbehaviour (not turning off water while brushing or shaving), and attempting to replace user habits (washing dishes under running water, drinking cold tap water) with greener activities. In the group of wise ways to use water for kitchen and bathroom equipment can be separated several subgroups. Belong to them:

- armature

- utensils and sanitary appliances

- white goods (dishwasher, washing machine)

- accessories (flow regulators, aerators, restrictors).

The capabilities of this group of solutions are constantly evolving. New technologies help. Among the more modern fittings solutions are the thermostatic faucets, the electronic sensors, the two-stage armature opening system and change the position of faucet lever in cold water mode. There are also innovative projects and solutions. Among them there are integrated sanitary utensils - a urinal combined with a washbasin and a sink combined with a toilet bowl through a flush. The second of these solutions can be found in Japan.

The dissemination of information and education of the general public is a very important factor in both the user-habits and kitchen and bathroom solutions. Also important are ways to convince people to save water, and here in turn can help smart city.

\subsubsection{Wise use of water in smart city}

The smart city vision is the idea of urban development using Information and Communication Technologies (ICT) and Internet of Things (IOT) technology. Through the use of ICT and IOT, it is also possible to support the wise use of water in cities and metropolises. By using appropriate monitoring sensor systems - data can be collected. Collections of such data may serve different purposes. Among them can be mentioned their analysis. Another goal may be an attempt to convince and encourage water users to save it. Examples of such practices may include the MK Smart project in the southern part of Great Britain in the Broughton area of Milton Kenyes [1]. From May 2016 to May this year, there was an attempt called Water Monitor [2]. Project participants (more than 100 households) through the website could check the weekly water consumption in their households and compare it with others, and also use advice on further minimization.

New technologies used within the broadly understood concept of smart city can help to indicate areas for action and upgrading. They can help highlight the problem and try to 
convince users to use water wisely and be their coach. It is important to note that the basics principle of water saving in households is man and his choice and the decision.

\subsection{Systems of evaluate tap fittings and its equipment}

Another way to support the decision-making process of water consumers in terms of saving it is the special evaluate systems of sanitary tapware and other equipment using water. Elements such as inter alia taps, showers, flow controllers, lavatories, urinals, clothing washing machines or dishwashers are subjects of evaluation.

There are several systems in the world for the classification of sanitary fittings and its fittings. Belong to them: the European Water Label scheme (formerly WEPLS - Water Efficient Product Labelling Scheme), the European scheme WELL (Water Efficiency Label) and the Australian WELS standards (Water Efficiency Labelling and Standards). Table 1 provides a comparison of basic information on the above three assessment systems. One can list both the example of the obligatory system covered by all the products sold within its jurisdiction and the non-mandatory system. For the latter, manufacturers voluntarily submit their goods for evaluation to gain added value to the product in the form of a mark of a prestige rating system. There are similarities and differences, but the goal of all systems is the same - saving water and energy.

Table 1. Comparison of three different systems of evaluate of tapware fittings and other sanitary equipment based on [3-10]

\begin{tabular}{|c|c|c|c|}
\hline $\begin{array}{c}\text { Feature/Name of } \\
\text { system }\end{array}$ & WELL & WELS & $\begin{array}{c}\text { Water Label } \\
\text { formerly WEPLS } \\
\end{array}$ \\
\hline full name of system & Water Efficiency Label & $\begin{array}{c}\text { Water Efficiency } \\
\text { Labelling and Standards }\end{array}$ & $\begin{array}{c}\text { Water Efficient } \\
\text { Product Labelling } \\
\text { Scheme ( till 2009) } \\
\text { Water Label } \\
\text { The European } \\
\text { Water Label } \\
\text { (launched 2012) }\end{array}$ \\
\hline country/countries & Europe & $\begin{array}{c}\text { Australia } \\
\text { New Zealand } \\
\end{array}$ & Europe \\
\hline subject to evaluation & voluntary & mandatory & voluntary \\
\hline $\begin{array}{l}\text { more important } \\
\text { documents }\end{array}$ & $\begin{array}{l}\text { WELL Classification } \\
\text { Scheme [3] }\end{array}$ & $\begin{array}{c}\text { Water Efficiency } \\
\text { Labelling and Standards } \\
\text { Act 2005 (WELS Act)[4], } \\
\text { AS/NZS 6400:2016 } \\
\text { Water Efficient Products } \\
\text { - Rating and Labelling } \\
\text { [5] }\end{array}$ & $\begin{array}{c}\text { Scheme Roadmap } \\
\& \text { Vision (Updated } \\
\text { 2017) [6] }\end{array}$ \\
\hline the rating scale & $\begin{array}{l}\text { rating using letter (A-F) } \\
\text { and star rating }\end{array}$ & star rating & $\begin{array}{c}\text { efficiency rating } \\
\text { from }>131 / \text { minute } \\
\text { up to max. } 6 \\
1 / \text { minute }\end{array}$ \\
\hline the highest mark & $\begin{array}{c}\text { A } \\
4 \text { stars for home } \\
\text { or } 6 \text { stars for public }\end{array}$ & 6 stars & $\max .61 /$ minute \\
\hline
\end{tabular}




\begin{tabular}{|c|c|c|c|}
\hline $\begin{array}{c}\text { Feature/Name of } \\
\text { system }\end{array}$ & WELL & WELS & $\begin{array}{c}\text { Water Label } \\
\text { formerly WEPLS }\end{array}$ \\
\hline the scope that covers & $\begin{array}{c}\text { wash basin } \\
\text { bidet valves } \\
\text { shower valves } \\
\text { shower heads } \\
\text { shower hoses } \\
\text { urinal flush systems } \\
\text { WC flush systems } \\
\text { accessories }\end{array}$ & $\begin{array}{c}\text { tap equipment } \\
\text { urinal equipment } \\
\text { lavatory equipment } \\
\text { showers } \\
\text { flow controllers } \\
\text { clothes washing machines } \\
\text { dishwashers }\end{array}$ & $\begin{array}{c}\text { baths } \\
\text { WC suites } \\
\text { cisterns } \\
\text { basin taps } \\
\text { shower controls } \\
\text { shower handsets } \\
\text { grey water } \\
\text { recycling units } \\
\text { kitchen taps } \\
\text { urinal controllers } \\
\text { electric showers } \\
\text { replacement WC } \\
\text { flushing devices } \\
\text { supply line flow } \\
\text { regulators } \\
\text { independent WC } \\
\text { pans }\end{array}$ \\
\hline $\begin{array}{l}\text { more important } \\
\text { sources }\end{array}$ & {$[3,7]$} & {$[4,5,8,9]$} & {$[6,10]$} \\
\hline
\end{tabular}

\subsection{Water consumption in Poland versus basic water needs}

In Poland water consumption in the last 30 years has changed. On the basis of data from Statistical Yearbooks [11] Figure 1 was prepared. It presents the changes in water consumption in Poland per capita between 1986 and 2015. Figure 1 also indicates the upper limit of basic water needs according to [12] and basic water requirements [13]. The highest water consumption in the analysed 30 years in Poland was recorded in 1987 and amounted to $196.2 \mathrm{dm}^{3} /$ capita/d. From this year to the year 2014 , there was a decrease in water consumption (except for 2007 and 2008, where water consumption was unchanged). An interesting situation took place in 2015, as water consumption this year increased again. In the following years it is expected to stabilize water consumption at around $100 \mathrm{dm}^{3} /$ capita/d or slightly less.

The basic water needs are determined by [12] as falling within the range of $7.5-15$ $\mathrm{dm}^{3} /$ person/d. The minimum amount of water required depends on, among other things, the climate, available sanitary facilities, religious and cultural customs and also the food that is cooked. In turn [13] suggests to assume a value of $50 \mathrm{dm}^{3} /$ person/d as the basic water requirement.

The difference between the cited minimum values and the current water consumption level in Poland shows that there is potential and opportunity to further reduce the consumption of tap water. The water consumption of 2015 in Poland $\left(94 \mathrm{dm}^{3} /\right.$ capita/d) in comparison with the value of [13] shows twice the difference. It should be borne in mind that the current technological development allows for much greater water savings with adequate living comfort than a dozen or so years ago. For this reason, more recent sources point to much lower minimum water needs. For this reason, the current literature sources indicate much lower minimum water requirements. 


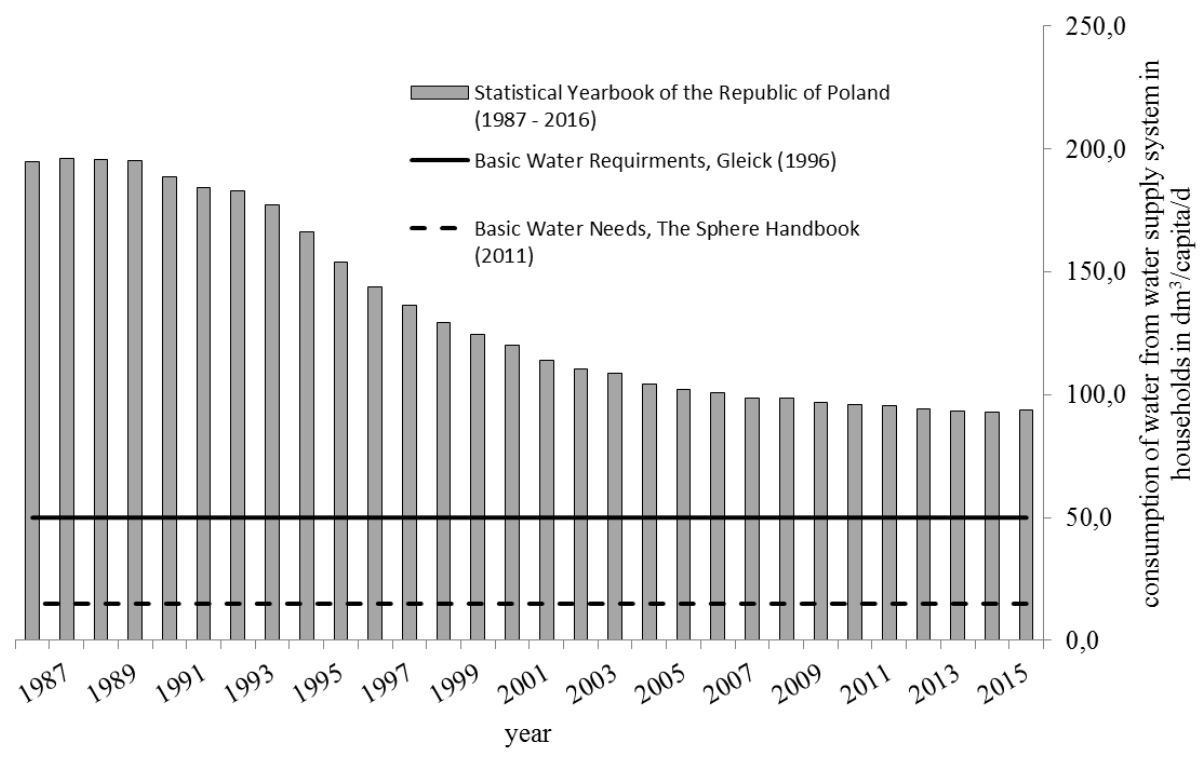

Fig. 1. Consumption of water from water supply system in households in Poland 1986 - 2015, based on data from [11] and basic water needs/requirements $[12,13]$

\section{Material and methods}

The outflow of cold water from the plumbing through the single lever basin mixers feature with different tap equipment (flow controllers and aerators) was investigated. The research was conducted in a household on the first floor in a large city in Poland. For comparison, the outflow from fittings without any tap equipment was also tested. Experiment was conducted as field test in the household in the private building under actual use conditions. For laboratory tests of flow regulators, the conditions set out in (PN - EN 246: 2005) [14] must be complied with.

Five new flow regulators which were marked in numbers 1 to 5 were tested (flow regulator $1 \div$ flow regulator 5 ). These water saving products have integrated technology which allows for compensating pressure. They are almost pressure independent. They produce different types of stream: spray jet, laminar jet without air intake and most popular aerated stream. They have also different structures, inter alia - honeycomb. In addition, one water saving aerator without special technology for compensating pressure was checked. Figure 2 shows all water consumption minimization products used in the study.

The outflow from the faucet was tested by the substituted vessel method. For this purpose, the water draining from the fitting spout was collected for 20 seconds and then the volume was gauged with measuring cylinder of $500 \mathrm{ml}$ capacity. Time is measured with an electronic stopwatch. The discharge from the faucet equipped with each flow regulator was tested several times in each series and then the result was averaged. Due to the possibility of changing the pressure in the installation, two series of measurements were made during various times of the day for inspection. The first series of measurements was performed during the day between 10.30 and 12.40, and the second at night between 00.30 and 02.15. Both series of research were conducted during the weekend. 


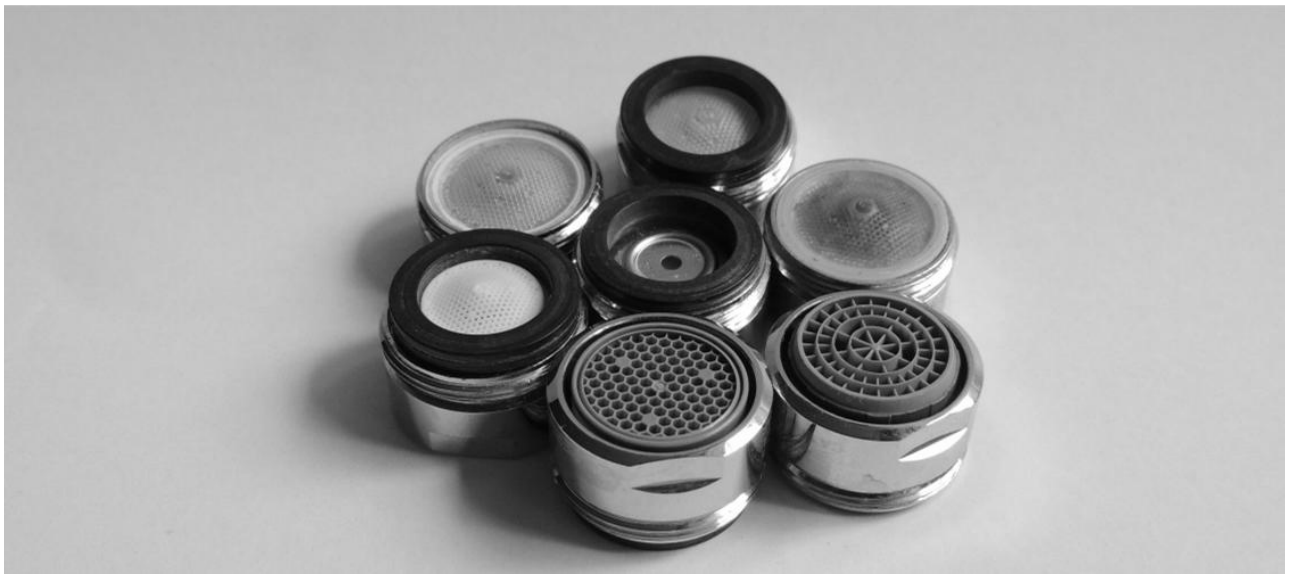

Fig. 2. All water-saving products used in the tests performed

At the present time very rarely occurrence of faucet without an aerator. In addition, the outflow from the tapware without any aerator and flow regulator showed some changes in subsequent tests. For these reasons, the reference level in the calculation was the outflow of the fittings provided with the old used water saving product. This has minimized the effect of pressure changes on the results obtained, since all flow regulators (including old product) were almost pressure independent.

The water used for the study has been reused for watering the backyard garden.

\section{Results}

The results of the study on the outflow from fittings supplied with different type of flow controllers are shown in Figure 3. In three out of seven tested outflows, there was no difference between the daily series and the night series. In other cases, the difference was small and was $0.1 \mathrm{dm}^{3} / \mathrm{min}$.

Before the comparison of the different tap equipment, a statistical evaluation of the obtained volume results for the used flow regulator, five new flow regulators and one aerator called tap equipment (daily series and night series) were carried out. The calculations were carried out in the Statistica 10 program.

It was checked whether the averages are the same for individual equipment of the faucet. Before starting a one-way analysis of variance, the assumptions of this parametric test were checked. The normality of the distribution was confirmed for all equipment by Shapiro - Wilk test, with the exception of aerator. Therefore, the homogeneity test and analysis of variance were performed for all measurements in each series and excluding the results for aerator. On the basis of the Brown - Forsythe homogeneity test, there is no basis for rejecting the null hypothesis with the equality of variances for both the daily series $(\mathrm{p}=$ 0.7961 for all results and $\mathrm{p}=0.7725$ excluding measurements for aerator) as well as for the night series $(p=0.5962$ and $p=0.6260$, respectively). Analysis of variance showed the significance of the differences between the considered averages for each series. In addition, post-hoc tests (multiple comparisons) were carried out. The results for the aerator were excluded due to the lack of confirmation of the normal distribution. The Tukey and Scheffe tests confirmed the significance of the differences between the average volume values in each series.

In addition, Kruskal - Wallis non-parametric test was carried out. Daily and night series of results were tested. The obtained test probability level $\mathrm{p}=0.0032$ allowed the rejection of the null hypothesis. The results of the analysis allow to conclude that the type of tap 
equipment used has a statistically significant impact on the volume of the outflow from the single lever basin mixers feature.

The percentage reduction of the outflow of faucet with new tap equipment compared to the old used flow regulator (but good quality with the possibility of easy lime cleaning) was calculated. Calculations were made for both series of tests. The results are presented in Table 2. Between the results of the various series there were no differences or differences of $1-2 \%$. By adopting less favourable percentages of reduction, it can be observed that the water flow has been reduced from $34 \%$ to $79 \%$. By adopting a hands wash duration of 15 seconds, using newer products it is possible to save from 0.7 to 1.7 litres with a single hands wash. The amount of water consumed for this activity can be minimized up to 0.4 litres (although there are commercially available products that allow even greater reduction the outflow). The outflow from a tap fitted with a new product accounts for even only $20 \%$ of the current outflow. By contrast, compared to the outflow from the fittings without any regulating or aerating product, the new products allow to reduce the flow even to $12-14 \%$ of the current outflow. In the comparison of all used water saved products with no flow controller state, the stream reduction value ranged from $34 \%$ to $88 \%$.

Studies show that it is possible to further minimize water consumption in households (even if good quality flow regulators have been used for some years). It is possible to achieve a reduction in the flow rate of up to about $80 \%$. However, it should be borne in mind that the savings introduced should not cause a loss of comfort of consumers. Extreme flow reduction can be used in households with young children learning to use sanitary utensils.

Research on the use of high efficiency water saving devices in households was conducted i.a. in the United States. A study [15] published in 2004 by the Tampa Water Department and United States Environmental Protection Agency (EPA) showed that modernization of houses into water saving devices (including aerators) allowed to reduce daily water consumption by an average $46 \%$ for household. The use of aerators enabled to save of almost $14 \mathrm{~m}^{3}$ per year.

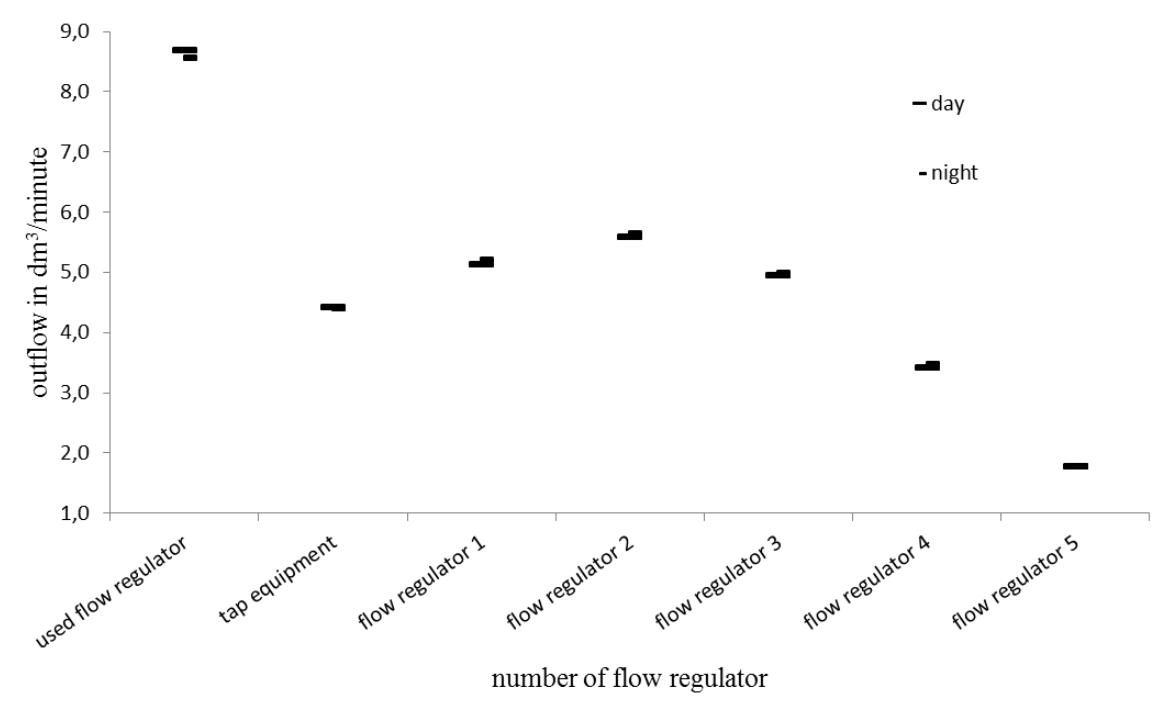

Fig. 3. The outflow from different flow regulators during daylight hours and during the night hours 
Table 2. The percentage of reduction in the outflow

\begin{tabular}{|l|c|c|}
\hline \multirow{2}{*}{ Number of flow regulator } & \multicolumn{2}{|c|}{$\begin{array}{c}\text { reduction in the outflow } \\
\end{array}$} \\
\cline { 2 - 3 } & day series & night series \\
\hline Tap equipment & 49 & 49 \\
\hline Flow regulator 1* & 41 & 39 \\
\hline Flow regulator 2* & 36 & 34 \\
\hline Flow regulator 3* & 43 & 42 \\
\hline Flow regulator 4* & 61 & 59 \\
\hline Flow regulator 5* & 80 & 79 \\
\hline
\end{tabular}

* statistically significant difference

\section{Summation and conclusions}

The basic constraint in saving water in households is not money at all, but man. State-ofthe-art technologies will not help much without a human being's decision to use them. Already very small investments, like the order of 5 - 10 euros, in modern flow controllers, can allow for significant savings. It is important that the benefits of minimizing water use are multifaceted. Water, energy (in case of reducing hot water consumption) and the environment are saved.

On the basis of the conducted research it can be concluded that replacing the current flow regulator with newer products, the consumption of water in the household can be reduced by up to $79 \%$. The other question is the efficiency of aerators limiting the flow after a certain period of time. This problem sets out a further direction of research in which the water quality (general water hardness) will also be important.

There is another side of this issue. It is less likely, but it should also be considered. It is worth bearing in mind that the vast majority of large and modern towns and cities are already equipped with a water supply network. Thus, pipelines of a certain diameter projected and selected by the designers already exist. If the water consumers will follow the guidelines for minimizing water consumption, they will implement mentioned solutions that will reduce usage of water and, in addition, the process will be large scale and take place in short term, there is a risk of secondary water contamination in the water supply network due to changes in network performance (e.g. velocity of water). Changes in these parameters may occur due to reduced demand for water by the inhabitants, and thus inseparable - reduced flow rate of water - at the same diameter of the pipeline. At the same time, the population is constantly moving into large and modern cities, new housing estates are being built there, so new buyers are emerging. It can therefore be assumed that possible changes in water demand resulting from consumption limitation are balanced by new consumers in the city and there is no significant risk of water contamination for this reason. It is important to monitor and, if necessary, adapt existing infrastructure to the evolving needs of society when adopting new directions for action and implementing sustainable development as well as, in particular, sustainable consumption (water). In addition to 
modern technology, the effective and substantive education (persuading to implementing changes) of the public in this area is still a key task.

\section{References}

1. The MK Smart project http://www.mksmart.org/water/\#1 access (2017)

2. MK: Smart Water Monitor watermonitor.mksmart.org access (2017)

3. WELL Water Efficiency Labelling Classification Scheme European Valve Manufacturer Association, http://www.well-online.eu (2016)

4. Water Efficiency Labelling and Standards Act 2005 as amended No.4 (2005)

5. AS/NZS 6400:2016 Australian/New Zealand Standard. Water Efficient Products Rating and Labelling (2016)

6. Y. Orgil, Scheme Roadmap \& Vision, http://www.europeanwaterlabel.eu/scheme_roadmap.asp, access (2017)

7. The WELL Water Efficiency Label website, www.well-online.eu access (2017)

8. WELS product database https://wels.agriculture.gov.au/wels-public, access (2017)

9. The Water Rating website Water Efficiency Labelling and Standards (WELS) scheme, A joint government and industry program, www.waterrating.gov.au access (2017)

10. The European Water Label website www.europeanwaterlabel.eu access (2017)

11. Statistical Yearbooks of the Republic of Poland, Central Statistical Office, Warsaw (1987-2016)

12. The Sphere Project The Sphere Handbook. Humanitarian Charter and Minimum Standards in Humanitarian Response, The Sphere Project, http://www.spherehandbook.org/en (2011)

13. P.H. Gleick, M. IWRA, Water Int, 21, No.2, 83-92 (1996)

14. PN - EN $246: 2005$, European Standard. Sanitary tapware - General specifications for flow rate regulators - polish version (2005)

15. P.W. Mayer, W.B. DeOreo, E. Towler, L. Martien, D.M. Lewis, Tampa Water Department Residential Water Conservation Study. The impact of high efficiency plumbing fixture retrofits in single - family homes, Aquacraft, Inc. Water Engineering and Management (2004) 